\title{
Explorations and Practices on Cultivation of Innovative Talents in New Universities for Undergraduates-A Case of Marketing Majors in Harbin Finance University
}

\author{
Xin Liu \\ Harbin Finance University, Harbin150030, China \\ jophyliu@outlook.com
}

\begin{abstract}
Under the background of mass entrepreneurship and mass innovation, it is necessary to cultivate innovative talents in new universities for undergraduates. To train innovative talents, connotations of creativity shall be clarified. With the case of Harbin Finance University, problems with creativity cultivation are analyzed to provide references for cultivating innovative talents with respect to drafting plans for talent cultivation, establishing curriculum systems, fostering practical abilities and training faculty.
\end{abstract}

Keywords: New Universities for Undergraduates; Creativity; Quality Training.

\section{Introduction}

Under the macroscopic background of "mass entrepreneurship and mass innovation", new universities for undergraduates need to engage in constructive explorations and practices on the whole process of talent training, in order to become advanced applied universities and cultivate high-level creative talents. Many new universities for undergraduates have attached great importance to cultivate students' practical abilities since they were just merely junior colleges, and they can still draw lots of lessons from their past training of junior college students to train undergraduates' creativity. Since it was promoted into a university for undergraduates, Harbin Finance University has aimed to cultivate applied talents and somewhat acted as a role model in training creativity of marketing majors.

\section{Creativity and Requirements}

Creativity refers to one's ability to create novel things different from conventional things or those developed by ordinary people to accommodate social needs. Novel things include thoughts, theories, products, methods and inventions and so on. As subjects of creativity education, university students are supposed to meet following requirements: Firstly, they must have requisite knowledge, skills and attitudes; secondly, they are conscious of discovering and actively solving problems; thirdly, they think creatively and dare to innovate; fourthly, they are able to practise and cooperate. Therefore, for marketing majors, creativity is reflected from their marketing ideas, marketing methods, products, places, promotion and competitive strategies.

\section{Problems with Creativity Training in New Universities for Undergraduates}

\subsection{Necessity for Further Improving Top-down Designs}

Although it is proposed in universities that they shall reinforce and highlight innovations, new universities for undergraduates still fall behind in updating their concepts. In particular, traditional Chinese universities generally place more emphasis on "cramming" in imparting knowledge to students, but attach very little importance to creativity cultivation. The student management strategies that new universities for undergraduates retain hinder the cultivation of students' personalities which are important for creativity. As a consequence, it is still impossible for these universities to consider creative concepts in their top-down designs for talent training (including plans for talent training and corresponding reform measures) or incorporate these concepts into their education or teaching processes. 


\subsection{Necessity for Improving Creativity Training Processes}

With the deepening of teaching reform, new universities for undergraduates have made constant innovations in their teaching methods and techniques, but they still have some problems, which are mainly as follows: Firstly, the overall teaching plans of new universities for undergraduates are stereotypical. These universities usually draft their teaching plans according to other universities' and quite similar to the latter. Instead, they don't consider whether their teaching plans are pertinent or not in combination with their characteristics and features. In their teaching plans, they seldom pay attention to students' differences. Secondly, the new universities for undergraduates still use the teaching materials they ever utilized for teaching junior college students. Although some teachers adopt teaching materials for undergraduates, they still teach undergraduates in the same way as they taught junior college students. For instance, marketing teachers aren't informative about new social needs and related professional knowledge.

\subsection{Necessity for Further Improving Guarantee Mechanism for Creativity Cultivation}

First of all, the universities ought to increase their investments in hardware facilities. Investments in laboratory equipment and capacity for updating books collected in libraries are guarantees for improving students' creativity, but at present, some universities' performances are unsatisfactory in these aspects. Secondly, teachers must improve themselves. Only if they are creative can they cultivate creative students, whereas overall qualities of teachers must be improved in new universities for undergraduates, where faculty team building remains to be strengthened and teachers' abilities to guide students need to be further improved. Thirdly, teaching evaluation systems are unsuitable for improving creativity. In some teaching projects for cultivating creativity where outcomes aren't evident until a long period of implementation, some parts which can't be quantitatively measured are not objectively evaluated.

\section{Explorations and Practices on Creativity Cultivation - A Case of the Marketing Department in Harbin Finance University}

\subsection{Highlighting Creativity Cultivation in Talent Training Programs}

Creative talent training programs shall be drafted based on practices and surveys. Harbin Finance University is situated in Heilongjiang Province, so drafters of talent training programs shall carefully analyse economic development trends of this province as well as industries' and enterprises' needs for skilled talents. Conduct field surveys of enterprises to understand their needs. Surveys are conducted to know about work procedures and posts of enterprises, analyse relationships between enterprises and cultivation of students' creativity and identify capability modules for students' creativity, so as to draft better training programs for professional talents in accordance with job requirements and needs for career development. In addition, universities and enterprises shall collaborate with each other to determine basic outlines of the programs.

Talent training programs shall be innovated based on student training structures and industry characteristics, among which the latter shall be emphasized, because new universities for undergraduates must improve creativity dependent upon these characteristics. As the sole new university for undergraduates which has been named in finance, Harbin Finance University exhibits great vitality, which is a distinguishing feature of this university. To highlight its financial characteristics, Harbin Finance University has opened required courses such as Finance, Investments and Financial Marketing. Courses, including Market Research and Prediction, Commodity Science, Advertising, and Marketing Practices, are opened according to industry characteristics to strengthen students' accumulation of specialized knowledge, which can lay a foundation for cultivating students' creativity. 


\subsection{Establishing Curriculum Systems for Creative Talents based on Industry Needs}

The Marketing Department of Harbin Finance University focuses on cultivating students' creativity and establishes a " $5+1$ " curriculum system for talent training driven by creativity training. " 5 " implies courses about ideological and political theories, general education courses, specialized basic courses, professional courses and interdisciplinary courses, while "1" implies teaching practices.

Firstly, establish a theoretical teaching system particularly to impart knowledge necessary for creativity cultivation. According to professional logical relations, Harbin Finance University to optimize/integrate foundations, create course modules and set up general education/interdisciplinary courses around core courses. Specialized basic courses such as Marketing, Statistics, Market Research and Analysis) and specialized courses are opened so that students can acquire requisite professional knowledge.

Secondly, establish a practical teaching system for the major purpose of improving creativity. Instead of depending upon the course conditions like traditional practical teaching, this system highlights that practical teaching shall be authentic, comprehensive and effective. For instance, several types of practices (experiments of course programs, professional cognitive internship and social practices) are organized at varying levels (course programs, integrated programs and graduation programs). Take the Marketing Department for example. Marketing majors are required to conduct market surveys, collect, analyse and sort out market information pursuant to enterprises' needs for business development. Market survey reports are completed based on market survey findings to provide companies with the basis for decision making. Practices are arranged for students to improve their abilities to analyse consumer psychology, buying motives and behaviors as well as their capabilities of coping with customers' objections, in order that students can master market survey and analysis methods and skills, PR abilities, negotiation skills, new knowledge, new skills, capability of sustainable development, innovation skills, transferable occupational skills, and abilities to collect and process information over four years of undergraduate studies.

\subsection{Expanding Courses for "Creativity Cultivation in the Whole Process"}

In the meantime, students' classroom feedbacks are tracked and collected on a real-time basis in accordance with professional teaching plans and unified schedules of the school to draft pertinent plans for course teaching and build platforms for information communications between teachers and students. Reinforce tutoring of students after classes via Rain Classroom, QQ groups, WeChat groups and email. Attach importance to online course development and develop professional courses related to marketing. Deepen reform of teaching means; introduce task-driven methods, case studies and practices as teaching means; increase students' initiatives to learn.

Place an emphasis upon "promoting learning through competitions"; cultivate students' creativity and their abilities to participate in market competitions by organizing professional skills competitions. At present, marketing majors of Harbin Finance University are guided by their teachers through years of attempts and competitions. The competitions that students must take part in include National Competition for University Students' Market Survey and Analysis, "Challenge Cup", "Internet+" and "Inclusive Finance \& Youth Practice" Summer Vacation Competition for University Students. By carrying out these disciplinary contests, Harbin Finance University not only "promotes teaching, learning, reform and construction via competitions", but also cultivates and tests students' creativity.

\subsection{Deepening School-enterprise Cooperation to Enhance Faculty Building for Creativity Cultivation}

Teachers are indispensable for improving students' creativity. It is necessary to make up faculty teams by professional teachers and industry experts through school-enterprise cooperation, practice advisors and enterprise professionals' lecturing, in order that faculty teams can be diverse but not unitary. The universities' own teachers will be not only able to teach, but also can-do practical jobs by industrial attachment, industry practices and qualification authentication. Teachers from enterprises cooperate with professional teachers to guide teaching and practices in universities in lecturing, practical guidance, thematic lectures and tutorship on graduation theses. 
Above all, the new universities for undergraduates are supposed to organically integrate their conventional teaching experience for undergraduates with their education experience for cultivating creative talents, with a view to further improve their education and foster their extraordinary schoolrunning characteristics and strengths. Therefore, these universities shall innovate their talent training models and actively explore a way for them to cultivate creative applied talents according to their practical situation and new requirements for cultivating talents' qualities through mass education.

\section{Acknowledgments}

Planned Program of Heilongjiang Provincial Education Department, Project Number: GLC1318040; Heilongjiang Provincial Higher Education Teaching Reform Program, Project Number: SJGZ20170028.

\section{References}

[1]. Yu Xiaozhen. Research on Practices for Training Creative Talents Based on Overall Qualities. Education Approach, 2018(03), p.73-79+88.

[2]. Qin Wei. Brief Analysis on Creativity Training for Talents in Applied Universities for Undergraduates. Journal of The Chinese Society of Education, 2015(S1), p.155-156.

[3]. Wei Wenxuan. Tentative Discussion of Ways for Local Colleges and Universities to Train Students' Creativity in a New Economic Era. Ability and Wisdom, 2019(15), p.157-158.

[4]. Ren Wenjie, Zhu Haowen. Reseaerch on Training Outstanding Creative Talents in Universities from the Perspective of "Competence Models". China Adult Education, 2018(07), p. 20-24.

[5]. Wu Hongyin, Huang Juan. Research on Training Creative Thinking and Creative Talents. SciTech \& Development of Enterprise, 2018(11), p.251-252. 